\title{
What Is the Optimal Way to Deliver a Positive Activity Intervention? The Case of Writing About One's Best Possible Selves
}

\author{
Kristin Layous $\cdot$ S. Katherine Nelson $\cdot$ Sonja Lyubomirsky
}

(C) Springer Science+Business Media B.V. 2012

\begin{abstract}
A 4-week-long experiment examined the effects of a positive activity intervention in which students wrote about their "best possible selves" (BPS) once a week. We manipulated two factors that might affect the success of the happiness-increasing activity-whether the positive activity was administered online versus in-person and whether the participant read a persuasive peer testimonial before completing the activity. Our results indicated that the BPS activity significantly boosted positive affect and flow and marginally increased feelings of relatedness. No differences were found between participants who completed the positive activity online versus in-person. However, students who read a testimonial extolling the virtues of the BPS activity showed larger gains in wellbeing than those who read neutral information or completed a control task. The results lend legitimacy to online self-administered happiness-increasing activities and highlight the importance of participants' beliefs in the efficacy of such activities for optimum results.
\end{abstract}

Keywords Positive activity intervention - Happiness - Subjective well-being · Need satisfaction · Flow · Best possible selves - Testimonial · Online intervention

\section{Introduction}

As motivated beings, people are always looking for new challenges and forming evergreater aspirations. The increasingly chaotic modern world, however, with its distracting technologies (smartphones, Facebook) and ever present stressors (traffic, deadlines) may divert people's attention away from what makes life worth living. Individuals often hurry from task to task without pausing to make sure the activities to which they are rushing are fulfilling their deepest needs or helping them realize personally meaningful goals. The current paper focuses on how writing about their "best possible future selves" in various

Electronic supplementary material The online version of this article (doi:10.1007/s10902-012-9346-2) contains supplementary material, which is available to authorized users.

K. Layous $(\bowtie) \cdot S$. Katherine Nelson · S. Lyubomirsky

Department of Psychology, University of California, 900 University Ave., Riverside, CA 92521, USA

e-mail: klayo001@ucr.edu 
life domains (social, health, academic, and career) may help redirect people's motivation toward goals that will lead to a rewarding life. We investigated which particular ways to practice this activity would generate the largest gains in well-being and fulfillment of basic psychological needs. Specifically, we explored the role of administration format (online versus in-person), as well as the impact of a persuasive message from a peer lauding the virtue of the writing exercise.

Most people report that happiness is an important personal goal (Diener 2000), and research suggests that their aspiration is well-placed. Happiness is not just a hedonistic, self-centered pursuit-instead, it has been associated with numerous other-oriented positive outcomes, such as relatively more prosocial behavior, greater productivity and cooperation at work, and more successful relationships (see Lyubomirsky et al. 2005a, for a review). Thus, happiness not only feels good, it $i$ good-both for the individual and his or her community and society at large.

Unfortunately, however, a large percentage of people report happiness levels below the point of flourishing (Seligman 2011). Can these individuals' well-being be increased? Theory suggests that a substantial proportion of happiness may be under the individual's control through intentional activities (Lyubomirsky et al. 2005b). Furthermore, the growing literature on happiness-increasing strategies is highly promising (see Sin and Lyubomirsky 2009, for a meta-analytic review), indicating that activities such as counting one's blessings (Emmons and McCullough 2003; Lyubomirsky et al. 2005b), performing acts of kindness (Lyubomirsky et al. 2005b, Sheldon et al., in press), using one's strengths in a new way (Seligman et al. 2005), writing letters of gratitude (Boehm et al. 2011a; Lyubomirsky et al. 2011; Seligman et al. 2005), or writing about one's best possible self (Boehm et al. 2011a; King 2001; Lyubomirsky et al. 2011; Peters et al. 2010; Sheldon and Lyubomirsky 2006) can increase well-being.

Many questions about how and why positive activity interventions work, however, remain unanswered. Does the format in which the intervention is administered impact its effectiveness? Does bolstering participants' beliefs or confidence in a positive activity's efficacy affect how much they benefit from that activity? The current study used a positive activity intervention that involved writing about one's best possible selves (BPS). First, we examined the ability of the BPS activity to increase positive emotions, feelings of need satisfaction, and flow experiences - all hallmarks of a happy life (Deci and Ryan 2000; Diener et al. 2009). Second, we explored two boundary conditions that may affect the efficacy of this intervention-namely, whether the BPS activity is administered online versus in-person and whether participants learn about the value of the activity.

\subsection{Best Possible Selves}

Writing about personal and meaningful experiences can have positive effects on mental and physical health (see Frattaroli 2006, for a comprehensive meta-analysis). In a series of studies, Pennebaker and his colleagues found that writing about negative experiences or difficult transitions alleviated health problems and bolstered coping and well-being (e.g., Pennebaker and Beall 1986; Pennebaker et al. 1990; Pennebaker and Seagal 1999). Extending these findings, King and Miner (2000) asked participants to write about the positive aspects of a negative experience (i.e., what they had learned or how they had grown as a result of the experience) and also found health benefits. King (2001) hypothesized that the health benefits resulting from emotionally disclosive writing might be due to the selfregulatory nature of writing - that is, participants are able to express and make sense of their emotions, thereby feeling a greater sense of control over what they experienced. 
King (2001) predicted that writing about a positive self-regulatory process-namely, life goals_-would engender similar benefits as making meaning of negative experiences. Indeed, writing about one's best possible self-a representation of one's goals-has not only shown the same long-term health benefits as writing about a trauma (King 2001), but also been found to promote increases in satisfaction with life (Boehm et al. 2011a), positive affect (King 2001; Peters et al. 2010; Sheldon and Lyubomirsky 2006), optimism (Peters et al. 2010) and overall well-being (Lyubomirsky et al. 2011). Mirroring these findings, we hypothesized that the BPS activity used in our study would boost one aspect of subjective well-being-positive affect. In addition, extending past research, we predicted that, because the BPS intervention involves a goal-focused (or self-regulating) writing activity, it would stimulate the need satisfying feelings of autonomy, relatedness, and competence. Finally, because we anticipated participants to take steps toward achieving their espoused goals during the course of the study, we predicted that engaging in the BPS activity would prompt increases in flow experiences (Csikszentmihalyi 1990).

\subsection{The Importance of Need Satisfaction and Flow}

Self-determination theory proposes that humans have three inherent psychological needs that promote optimal motivation, development, and wellness (Deci and Ryan 2000, 2008): Autonomy (the feeling that one's actions are under one's control), competence (the feeling that one is effective and skilled), and relatedness (the feeling that one is close and connected to others in one's life). A great deal of research has accumulated to support the positive independent effects of each of these three needs on well-being and performance across cultures and contexts (Deci and Ryan 2008; Ryan and Deci 2008; Sheldon 2004). Feelings of need satisfaction have been associated with positive affect and (less) negative affect (Sheldon et al. 2001), and increases in need satisfaction have been shown to predict later increases in subjective well-being (Niemiec et al. 2009; Sheldon and Elliot 1999). Furthermore, research suggests that people can bolster their levels of need satisfaction through goal pursuit and well-suited goal choices (Niemiec et al. 2009; Sheldon and Elliot 1999; Sheldon and Krieger 2007), thus indicating that intentional activities can increase fulfillment of psychological needs.

Although the importance of need satisfying experiences has been well established in multiple life domains, including relationships, education, work, sport, and sustainable behaviors (Deci and Ryan 2008), their role in positive activity interventions has not been closely examined. In one exception, Boehm et al. (2011b) found happiness-increasing activities to increase autonomy and relatedness, and to lead to later increases in satisfaction with life. The current study sought to further examine the ability of happiness-increasing activities to bolster need satisfaction. Because of the strong link between goal pursuit and need satisfaction, the BPS activity - a goal focused activity - may be especially disposed to increase feelings of need satisfaction. Although we did not specifically ask participants to pursue their goals, we believed that writing about their future selves and setting goals to reach their targets were likely to have similar effects as actual goal pursuit.

Furthermore, because the BPS activity prompts participants to think about their ideal self, it is possible they may be reminded of (and be motivated to engage in) pastimes in which they felt completely engrossed in an activity that was enjoyable and meaningful to them-in other words, in a flow experience (Csikszentmihalyi 1990). A flow experience occurs when one is engaged in a challenging activity that matches one's skill level (Csikszentmihalyi and Hunter 2003). Being in a flow state has been described as having an out-of-body experience in which nothing else matters except what one is doing at that very 
moment (Nakamura and Csikszentmihalyi 2009). Although people are typically not selfaware during flow, they report afterwards that their experience had been intensely positive. Similarly, people who are often in flow report more positive states overall, as well as more meaning in their lives, than people who are not often in flow (Csikszentmihalyi 1999). Although flow is positively related to well-being (Nakamura and Csikszentmihalyi 2009), little research has examined whether engaging in positive activities can successfully increase feelings of flow. In this study, we expected the BPS activity to have a direct influence on flow.

\subsection{Online Versus In-Person Administration}

In addition to examining the effects of the BPS activity on positive affect, need satisfaction, and flow, we also sought to explore the boundary conditions that might make the intervention more or less successful. One factor that could potentially influence the efficacy of the BPS activity is the format in which the activity is administered. To explore this question, we manipulated whether participants completed the study in-person or online.

Online intervention programs have been found to successfully increase knowledge about and use of sunscreen (Armstrong et al. 2011), decrease binge eating behaviors (Carrard et al. 2011), facilitate weight loss efforts (Collinson et al. 2010), decrease depression and improve social functioning (Meyer et al. 2009), and reduce alcohol consumption and alcohol-related problems (Hester et al. 2011). Although preliminary results for online intervention programs are promising, to our knowledge, no research has been conducted directly comparing online programs to treatment-as-usual. One exception, however, is a review of interventions for drug use disorders, which found computer-based interventions to be more effective than treatment-as-usual in decreasing substance abuse, retaining participants, and increasing participant knowledge of the presented material (Moore et al. 2011).

In the positive psychology literature, many interventions have been conducted using an online self-administered format, but no studies have directly compared online administration to a directed in-person format. Evidence from a meta-analysis on positive psychology interventions suggests that interventions administered in one-on-one or group formats have better outcomes than interventions that are self-administered (Sin and Lyubomirsky 2009). Possibly the missing ingredients in self-administered formats are direct human contact and pre-arranged timeslots in which participants can focus on and practice the positive activity (Mitchell et al. 2010). On the other hand, the self-administered format may also have advantages over group and one-on-one formats that may offset the potential disadvantages. For example, self-administered interventions are convenient (i.e., they can be done whenever and wherever one finds the time) and anonymous (i.e., one does not have to show up in-person or tell anyone they are practicing a happiness-increasing activity; Layous et al. 2011; Mitchell et al. 2010). Finally, self-administered formats may be empowering to the individual, as any increases in well-being can be attributed to his or her own effort and not to an outside entity such as a support group or therapist (Layous et al. 2011; Mitchell et al. 2010).

A review of the respective advantages and disadvantages of group administered versus self-administered happiness-increasing activities did not point convincingly to a superior administration format. In the current study, we sought to verify the well-being benefits of practicing a BPS activity online (self-administered) compared to the benefits of practicing it in-person (group administered). Due to the potential advantages of each administration type, we predicted no substantive differences between the two procedural formats. Such findings would lend legitimacy to the more convenient and accessible online self-administered format. 


\subsection{Use of Peer Testimonials to Manipulate Perceptions of Activity Efficacy}

To examine a second boundary condition, we sought to manipulate our participants' beliefs or confidence in the efficacy or value of the BPS activity. Specifically, we gave some students bogus peer testimonial information (i.e., different students explaining how the study helped them) and gave other students generic, but arguably helpful, information for furthering goal pursuit (i.e., details regarding services provided on campus). Previous research supports that peer testimonials affect people's perceptions of their personal health risks (de Wit et al. 2008) and are influential when used in advertising (Martin et al. 2008); however, the influence of peer testimonials has not been studied in positive activity interventions. We hypothesized that participants who read a series of peer testimonials would be more likely to believe in the efficacy of the BPS activity and, consequently, to take the activity more seriously, put forth more effort, and gain more benefit from it.

Past research has demonstrated the importance of effort (Lyubomirsky et al. 2011), selfconcordant motivation (Sheldon and Lyubomirsky 2006) and attitudes towards happiness increasing activities (Sheldon et al. 2010) on the success of happiness-increasing activities. For example, in one study, people who self-selected into a so-called "happiness study" showed greater gains in well-being than people who self-selected into a "cognitive exercises study" (Lyubomirsky et al. 2011). Furthermore, participants who put more effort into completing their assigned activities, which involved either regularly expressing gratitude and optimism or writing about their day's activities, showed greater increases in well-being, but only when completing the positive activities (Lyubomirsky et al. 2011). Thus, it seems that people need both a will (motivation and effort) and a way (an effective positive activity) to become happier.

The type of motivation people have to engage in a happiness-increasing activity also plays an important role in the efficacy of the activity. Self-determination theory (Deci and Ryan 2000) suggests that extrinsically motivated activities (i.e., those that are done for external rewards) are less satisfying than intrinsically motivated activities (i.e., those that are done for one's personal satisfaction). Because the participants in the majority of psychological experiments are undergraduates who receive course credit for participation, we must consider them to be extrinsically motivated. However, even an extrinsically motivated activity can parallel an intrinsically motivated activity if the individual internalizes the activity and feels that it is congruent with her own values. Thus, it is possible that our peer testimonial manipulation will help prompt participants to internalize or identify with the BPS activity by giving them persuasive information regarding the activity's efficacy.

Recent research has suggested that valuing happiness too much may be detrimental to well-being (Mauss et al. 2011). To avoid this potential problem, our manipulation directly focused on the value of the BPS activity in its own right, rather than on the value of being happy in general. In addition, some past research has been limited in its reliance on correlational data (e.g., using self-selected participants or measuring effort via self-report). To overcome this shortcoming, we experimentally manipulated whether participants would receive the peer testimonial information.

\subsection{Overview of Current Study}

\subsubsection{Design}

Participants were randomly assigned to one of four experimental conditions or one of two control conditions. Accordingly, we used a 2 (online vs. in-person administration) $\times 3$ (peer testimonial vs. no testimonial vs. control) $\times 2$ (baseline vs. follow-up) design. Three 
of the conditions were completed in in-person sessions with a research assistant administering the study each week, and three of the conditions were completed online. The three in-person conditions mirrored the online conditions exactly. Two of the six conditions (No Testimonial/Online and No Testimonial//n-Person) were BPS conditions in which participants were given instructions to write about their "best possible selves" in a different domain of their life each week (academics, social, career, and health). Participants in these conditions were provided objective information about how to complete the writing task and what resources are available on campus pertaining to that week's targeted life domain. They were not, however, given any persuasive information to believe that the BPS task would help them clarify and reach their goals.

Participants in the two peer testimonial BPS conditions (Peer Testimonial/Online and Peer Testimonial/In-Person) were administered the same writing instructions as the no testimonial participants, but, instead of reading a neutral paragraph describing campus resources, they read a (bogus) quote from a fellow college student who allegedly completed this same writing activity about 1 year earlier. The quote was meant to persuasively illustrate the efficacy of the BPS writing activity to help students formalize their ideal version of themselves in various life domains and to motivate them to take steps toward achieving that ideal.

In both of the neutral control conditions (Control/Online and Control/In-Person), participants were simply instructed to list what they did over the past $24 \mathrm{~h}$.

\section{Method}

\subsection{Participants}

Participants were 131 introductory psychology students at a diverse medium-size public university (94 female, 37 male), who completed the study for course credit. The majority were Asian American (30\%), Caucasian (19.3\%), or Hispanic/Latino(a) (18\%). The remaining participants were Black/African American (9.3\%), more than one ethnicity (5.3\%), "other" (4.7\%), or Hawaiian/Pacific Islander $(0.7 \%)$. Their average age was 19.10 years $(\mathrm{SD}=1.77)$, with a range from 18 to 28 years.

\subsection{Procedure}

The study was advertised on the Department of Psychology's subject pool website as a study about "writing and emotions," with a brief description stating that participants would engage in writing activities each week and complete questionnaires regarding their emotions. After students signed up for the study, they were directed to an external website on which they logged in and were randomly assigned to one of the six conditions.

Participants assigned to one of the in-person conditions were scheduled for a $45-\mathrm{min}$ small-group (4-10 person) session with participants in the same condition. Students assigned to one of the online conditions were instructed to wait for an email before logging back into the site to complete the first phase of the study. In the first in-person meeting (for the in-person participants) and second website log-in (for the online participants), participants gave consent, completed baseline measures, and then completed their first writing activity.

Regardless of condition, students participated in the study once a week for 4 weeks for a total of four writing activities. Each week, they received reminders either to attend their scheduled group session (in-person participants) or to log-into the website to complete the study activities (online participants). 
The final sample sizes per cell were as follows: Peer Testimonial/In-Person $(n=25)$, No Testimonial/In-Person $(n=25)$, Control/In-Person $(n=23)$, Peer Testimonial/Online $(n=16)$, No Testimonial/In-Person $(n=15)$, and Control/Online $(n=15){ }^{1}$

\subsection{Activity Instructions}

To minimize demand characteristics, all participants were told that the activity was designed to improve their well-being. The basic writing instructions were the same in the four BPS conditions (Peer Testimonial/In-Person, No Testimonial/In-Person, Peer Testimonial/Online, and No Testimonial/In-Person) each week, with personalized examples about the four specific life domains (academic, social, career, or health) inserted. For example, during the academics week, participants were asked to "take a moment to think about your best possible academic life during your time in college. Imagine that everything has gone as well as it possibly could. Perhaps you have successfully chosen a major or concentration that you enjoy and are achieving good grades in your classes. Think of this as the realization of the best possible academic life you could ever hope for yourself."

Participants were then asked to write continuously for $10 \mathrm{~min}$, being as creative and imaginative as they want, using whatever writing style they chose, and using as much detail as they want. Students were also informed that their words would be strictly confidential. After the $10 \mathrm{~min}$ were complete, they were then asked to take $5 \mathrm{~min}$ to write a more specific goal or goals that would help them attain their best possible selves. The specific instructions were as follows:

Now, write down a goal (or goals) you think you might want to attain that will help you achieve your best possible self that you just described. Sometimes long-term goals seem overwhelming or out of your reach. But every journey begins with just a single step. Think about taking baby steps towards your long-term goal (or goals). A baby step could be as simple as proactively seeking information you need or talking to someone who may be able to guide you. Defining the next baby step you need to take to get a little closer towards your goal is a great way to get going with the journey without worrying too much about the length of the road.

\subsubsection{Peer Testimonial}

In addition to the basic BPS instructions described above, participants in both online and in-person peer testimonial conditions also read a bogus quote from a fellow college student who was said to have performed this writing activity the previous year. The quote for each specific life domain was tailored toward that domain, but every quote had the same basic message-namely, that the BPS writing activity had helped the students clarify their goals and take steps to making progress within that life domain. Participants were asked to "Please read this excerpt from a follow-up done with a student who participated in a similar study last year." The specific testimonials used for each life domain are provided in the Electronic Supplementary Information.

\footnotetext{
${ }_{1}$ Due to a website glitch, 19 participants from the online conditions were unable to complete baseline measures and therefore were not included in the demographic statistics or subsequent analyses. Further, 12 online participants were eliminated from analyses because they failed to log-in at the post-intervention time point. No significant baseline differences were found between participants who were included in the final analyses and those who only completed baseline measures.
} 


\subsubsection{No Testimonial}

Along with the basic BPS instructions, students in both online and in-person no testimonial conditions read objective, seemingly neutral information about campus resources related to the life domain of the week. Participants were told, "Here is some information about [academics, social life, career exploration, or health] at UCR." The specific excerpts for each life domain are presented in the Electronic Supplementary Information.

\subsubsection{Control}

Participants in the control activity were asked to "Please take a moment to think about what you did during the last $24 \mathrm{~h}$. That is, create a mental outline of what you did during that time. Now, for the next $10 \mathrm{~min}$, please write out these activities in a list format. Be as detail oriented as possible, but try to leave out emotions, feelings, or opinions pertaining to your plans. In other words, focus on exactly what you did." Students were also told they can write in any style they want and that their answers would remain completely confidential. After the $10 \mathrm{~min}$ had elapsed, control participants were then asked to expand upon one of their activities listed in greater detail: "Now choose one of the activities you listed and write about it in even more detail (i.e., instead of just saying 'I studied for my calculus midterm,' say 'I reviewed various sample problems off of the study guide and re-read chapters $4,5 \& 6$. After that, I got together with some people from my class and discussed the main concepts that might show up on the test.') You want to dissect the activity you previously listed into smaller pieces to describe exactly what you did."

\subsection{Materials}

\subsubsection{Consent and Background Information}

Participants who were randomly assigned to one of the in-person conditions were given a consent form that described the study and their rights as participants during their first inperson session. They were verbally informed that signing the consent form would establish their consent to participate in the study. Once students signed and turned in the consent form, they were then asked to fill out demographic information and baseline information. Participants who were randomly assigned to one of the online conditions were shown the same consent form as the in-person participants upon their second log-into the study website. (The first log-in was just for random assignment and a welcome message.) They were informed that clicking "next' would affirm their consent to participate in the study. After clicking "next," students in the online condition completed demographic information and baseline measures on the study website.

\subsubsection{Positive Affect}

To measure positive affect, we used a subset of the Affect-Adjective Scale created from emotion terms that loaded strongly onto positive and negative affect factors (Diener and Emmons 1985). Participants were asked to rate the extent to which they have felt each emotion (e.g., happy, pleased, joyful, enjoyment/fun) in the past week on a 7-point scale $(0=$ not at all, $6=$ extremely $)$. Cronbach's $\alpha$ coefficients were .89 at baseline and .93 at post-intervention. 


\subsubsection{Need Satisfaction}

Based on self-determination theory (Deci and Ryan 2000), this measure assesses the degree to which students' core needs are being met (Sheldon et al. 2001). Participants were asked to "rate the extent to which they have felt the following ways during the past week (last 7 days)" on a 7 -point scale $(1=$ not at all, $7=$ very much $)$. Nine need satisfying feelings were listed, three representing autonomy (e.g., "I felt that my choices were based on my true interests and values"), three representing relatedness (e.g., "I felt a sense of contact with people who care for me, and whom I care for"), and three representing competence (e.g., "I felt that I was taking on and mastering hard challenges"). Results were analyzed by combining all nine items into a "need satisfaction" composite $(\alpha=.86$ at baseline and .92 at post-intervention), as well as examining autonomy $(\alpha=.68$ at baseline and .82 at post-intervention), relatedness $(\alpha=.83$ at baseline and .91 at post-intervention), and competence ( $\alpha=.73$ at baseline and .81 at post-intervention) as separate variables.

\subsubsection{Flow}

A 5-item scale was used to measure how much flow participants had been experiencing (Csikszentmihalyi 1990). Like the need satisfaction items, participants were asked to rate the degree to which they had felt the following way(s) during the past week on a 7-point scale $(1=$ not at all, $7=$ very mисh $)$. Items included "I felt very stimulated and challenged" and "I felt very absorbed in what I was doing." Cronbach's $\alpha$ coefficients were .77 at baseline and .85 at post-intervention.

\section{Results}

\subsection{Overview of Primary Analyses}

Students' positive emotions, need satisfaction, and flow were assessed during the first week (i.e., before the manipulation; baseline) and during the intervention's fourth and final week (i.e., immediately after the last writing activity: post-intervention). To test our hypotheses, we performed planned contrasts on the difference scores (baseline scores subtracted from post-intervention scores $)^{2}$ for each of our variables: Positive emotions, need satisfaction, the components of need satisfaction separately (autonomy, relatedness, competence), and flow (see Rosenthal et al. 2000, for a detailed review of contrast analysis).

An initial planned contrast compared the four BPS conditions to the two control conditions. A second planned contrast compared the in-person BPS conditions to the online BPS conditions, leaving the control groups set aside. A third planned contrast compared the use of peer testimonial information to no information and to the control groups, predicting that BPS

\footnotetext{
${ }^{2}$ We used analyses of difference scores as a straightforward and natural approach to test differences in change over time. Because we expected well-being to remain stable without our intervention, the underlying assumptions of difference scores (vs. covariance analysis) seemed appropriate (Wainer 1991). In addition, because we randomly assigned participants to condition-eliminating any baseline differences in well-being among conditions - covariance analysis had no advantages over difference scores (Maris 1998). Finally, Rogosa (1988) dispels the myth that difference scores are unreliable, particularly when the correlations between the Time 1 and Time 2 measures are moderate, suggesting that true change is present. Indeed, the correlations between the Time 1 and Time 2 scores in our study (mean $r=.43$ ) are moderate by conventional standards.
} 
conditions that included peer testimonial information would boost well-being more than BPS conditions with no testimonial, but that the no testimonial group would boost well-being more than the control activity. To further disentangle this pattern of results, this contrast analysis was also performed separately in the online and in-person conditions. See Table 1 for contrast weights and mean changes in well-being for the above three contrast analyses.

\subsection{Baseline Analyses}

To examine the presence of group differences prior to our manipulation, we conducted a series of analyses on the baseline measures. One-way analyses of variance revealed no significant differences in baseline well-being among our conditions (all $F \mathrm{~s}<1.8, n s$ ), suggesting that random assignment was successful. In addition, no significant differences were found based on participant sex (all $F \mathrm{~s}<2.6, n s$ ) or ethnicity (all $F \mathrm{~s}<1$. 2, ns), so all subsequent analyses were collapsed across these demographics. All analyses are reported using one-tailed $p$ values.

\subsection{Changes in Well-Being}

\subsubsection{Efficacy of BPS activity}

Supporting our hypothesis, planned contrast analyses revealed that participants who performed the BPS activity showed bigger increases in positive affect $\left[t_{\text {contrast }}(115)=1.85\right.$, $\left.p=.03, r_{\text {contrast }}=.17.\right]^{3}$ and flow $\left[t_{\text {contrast }}(117)=1.83, p=.03, r_{\text {contrast }}=.17\right]$ than participants who performed the control activity. A marginally significant difference relative to the control group also emerged for relatedness $\left[t_{\text {contrast }}(117)=1.47, p=.07\right.$, $\left.r_{\text {contrast }}=.13\right]$. No significant differences between the BPS and control conditions were found for our other primary variables (i.e., autonomy, competence, or the need satisfaction composite; all $t_{\text {contrasts }}<1, n s$.

\subsubsection{Online Versus In-Person Administration}

Next, we explored potential differences between administering the intervention in-person or online. For this analysis, the control conditions were set aside. A planned contrast revealed that students in the online BPS conditions did not experience significantly different changes in well-being than participants in the in-person BPS conditions on any of our outcome variables (all $\left.t_{\text {contrasts }}<\mid 1.22 \mathrm{l}, n s\right) .{ }^{4}$

\subsubsection{Peer Testimonial Versus No Peer Testimonial}

A third focused analysis tested the role of peer testimonial information in bolstering the efficacy of the BPS intervention. The hypothesis was supported for positive affect

\footnotetext{
3 Two additional online participants did not answer questions related to positive affect at baseline but completed the need satisfaction items and were therefore included in those analyses. This resulted in the need satisfaction analyses having two more degrees of freedom than the positive affect analyses.

4 Due to the unequal sample sizes in the in-person condition $(n=50)$ and the online condition $(n=30)$ for this analysis, we calculated the relative loss of power (Rosenthal and Rosnow 2008) of the unequal- $n$ design to the equal- $n$ design as .06, which is comparable to losing a total of 5 participants in an equal- $n$ design. Therefore, it is unlikely that these nonsignificant findings resulted from loss of power due to an unequal$n$ design.
} 
Table 1 Means (SDs) for changes in well-being by experimental condition (top), type of administration (middle), and peer testimonial group

\begin{tabular}{|c|c|c|c|c|c|c|}
\hline \multirow{3}{*}{ Contrast weight $(\lambda)$} & \multicolumn{6}{|c|}{ Experimental condition } \\
\hline & \multicolumn{3}{|c|}{ Intervention $(+1)$} & \multicolumn{3}{|c|}{ Control $(-1)$} \\
\hline & \multicolumn{2}{|c|}{$\mathrm{M}(\mathrm{SD})$} & $\mathrm{n}$ & \multicolumn{2}{|c|}{$\mathrm{M}(\mathrm{SD})$} & $\mathrm{n}$ \\
\hline Positive affect & \multicolumn{2}{|c|}{$0.26(1.30)$} & 80 & \multicolumn{2}{|c|}{$-0.23(1.40)$} & 37 \\
\hline Need satisfaction & \multicolumn{2}{|c|}{$0.03(1.04)$} & 81 & \multicolumn{2}{|c|}{$-0.15(1.11)$} & 38 \\
\hline Autonomy & \multicolumn{2}{|c|}{$-0.10(1.20)$} & 81 & \multicolumn{2}{|c|}{$-0.25(1.42)$} & 38 \\
\hline Competence & \multicolumn{2}{|c|}{$0.15(1.20)$} & 81 & \multicolumn{2}{|c|}{$0.11(1.33)$} & 38 \\
\hline Relatedness & \multicolumn{2}{|c|}{$0.06(1.33)$} & 81 & \multicolumn{2}{|c|}{$-0.32(1.28)$} & 38 \\
\hline \multirow[t]{2}{*}{ Flow } & \multicolumn{2}{|c|}{$0.12(1.11)$} & 81 & \multicolumn{2}{|c|}{$-0.29(1.26)$} & 38 \\
\hline & \multicolumn{6}{|c|}{ Administration type } \\
\hline \multirow[t]{2}{*}{ Contrast weight $(\lambda)$} & \multicolumn{2}{|c|}{ In-person $(+1)$} & \multicolumn{2}{|l|}{ Online $(-1)$} & \multicolumn{2}{|l|}{ Control (0) } \\
\hline & $\mathrm{M}(\mathrm{SD})$ & $\mathrm{n}$ & $\mathrm{M}(\mathrm{SD})$ & $\mathrm{n}$ & $\mathrm{M}(\mathrm{SD})$ & $\mathrm{n}$ \\
\hline Positive affect & $0.12(1.39)$ & 50 & $0.49(1.12)$ & 30 & $-0.23(1.39)$ & 37 \\
\hline Need satisfaction & $-0.01(1.11)$ & 50 & $0.10(0.95)$ & 31 & $-0.15(1.11)$ & 38 \\
\hline Autonomy & $-0.13(1.31)$ & 50 & $-0.05(1.00)$ & 31 & $-0.25(1.42)$ & 38 \\
\hline Competence & $0.13(1.33)$ & 50 & $0.18(1.01)$ & 31 & $0.11(1.33)$ & 38 \\
\hline Relatedness & $-0.03(1.33)$ & 50 & $0.18(1.33)$ & 31 & $-0.32(1.28)$ & 38 \\
\hline \multirow[t]{2}{*}{ Flow } & $0.03(1.13)$ & 50 & $0.27(1.08)$ & 31 & $-0.29(1.26)$ & 38 \\
\hline & \multicolumn{6}{|c|}{ Peer testimonial group } \\
\hline \multirow[t]{2}{*}{ Contrast weight $(\lambda)$} & \multicolumn{2}{|c|}{ Peer testimonial $(+2)$} & \multicolumn{2}{|c|}{ No testimonial $(+1)$} & \multicolumn{2}{|l|}{ Control $(-3)$} \\
\hline & $\mathrm{M}(\mathrm{SD})$ & $\mathrm{n}$ & $\mathrm{M}(\mathrm{SD})$ & $\mathrm{n}$ & $\mathrm{M}(\mathrm{SD})$ & $\mathrm{n}$ \\
\hline Positive affect & $0.27(1.52)$ & 40 & $0.25(1.06)$ & 40 & $-0.23(1.40)$ & 37 \\
\hline Need satisfaction & $0.04(1.09)$ & 41 & $0.03(1.01)$ & 40 & $-0.15(1.11)$ & 38 \\
\hline Autonomy & $-0.09(1.27)$ & 41 & $-0.11(1.13)$ & 40 & $-0.25(1.42)$ & 38 \\
\hline Competence & $0.14(1.18)$ & 41 & $0.17(1.24)$ & 40 & $0.11(1.33)$ & 38 \\
\hline Relatedness & $0.07(1.48)$ & 41 & $0.05(1.18)$ & 40 & $-0.32(1.28)$ & 38 \\
\hline Flow & $0.14(1.13)$ & 41 & $0.11(1.10)$ & 40 & $-0.29(1.26)$ & 38 \\
\hline
\end{tabular}

$\left[t_{\text {contrast }}(114)=1.82, \quad p=.04, \quad r_{\text {contrast }}=.17\right]$ and flow $\left[t_{\text {contrast }}(116)=1.82, \quad p\right.$ $\left.=.04, r_{\text {contrast }}=.17\right]$ and marginally supported for relatedness $\left[t_{\text {contrast }}(116)=1.45\right.$, $\left.p=.07, r_{\text {contrast }}=.13\right]$. The combined need satisfaction variable, as well as autonomy, however, failed to reach significance (both $t_{\text {contrasts }}<0.9$ ).

\subsubsection{Peer Testimonial in Online Conditions}

To explore the conditions under which peer testimonial information was most impactful, we ran two additional contrast analyses. One specifically tested the peer testimonial hypothesis in the online conditions with the in-person conditions set aside, and one specifically tested the hypothesis in the in-person conditions with the online conditions set aside. See Table 2 for contrast weights and mean changes in well-being by condition. 


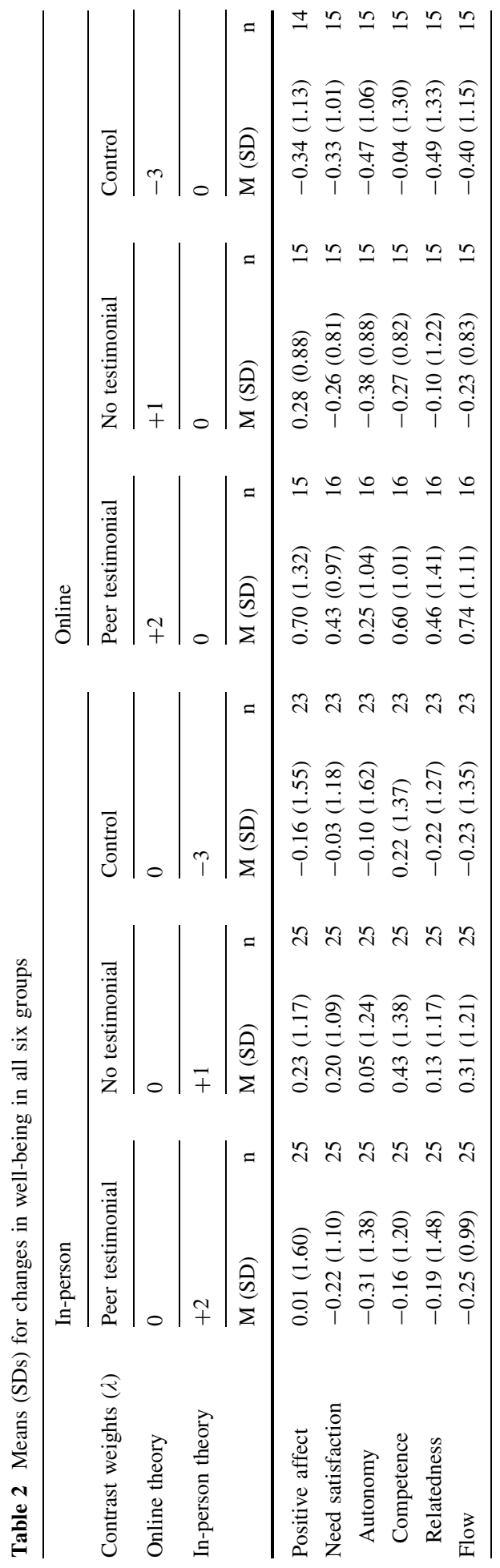


Analyses of the online conditions strongly supported our hypothesis about the influence of peer testimonials in a BPS intervention. Accordingly, 1) participants in the peer testimonial condition showed greater increases than participants in the no testimonial condition and 2) both intervention conditions showed greater increases than the control condition in positive affect $\left[t_{\text {contrast }}(41)=2.05, p=.02, r_{\text {contrast }}=.30\right]$, relatedness $\left[t_{\text {contrast }}(43)=\right.$ $1.81, p=.04, r_{\text {contrast }}=.27$, and flow $\left[t_{\text {contrast }}(43)=2.26, p=.01, r_{\text {contrast }}=.33\right]$. Our hypothesis was also marginally supported for need satisfaction $\left[t_{\text {contrast }}(43)=1.59\right.$, $\left.p=.06, r_{\text {contrast }}=.24\right]$ and autonomy $\left[t_{\text {contrast }}(43)=1.25, p=.11, r_{\text {contrast }}=.19\right]$, but not for competence $\left[t_{\text {contrast }}(43)=0.92, n s\right]$. In contrast, when the peer testimonial hypothesis was tested in the in-person format, no significant effects were found for any of our outcome variables (all $t_{\text {contrasts }}<0.8$ ).

\section{Discussion}

Most people express a desire to be happy, but often do not pause their busy lives to contemplate what they truly want out of life or to engage in activities and experiences that bring them joy or contentment. The current study prompted people to take a moment to write about their ideal future selves. Although we did not require participants to take any steps toward the goals they espoused, we predicted that simply writing about their best possible selves would increase well-being. Indeed, both theory (Lyubomirsky et al. 2005b) and research (Sin and Lyubomirsky 2009) suggest that people can increase their personal levels of well-being through the intentional practice of relatively simple positive activities.

Research also suggests, however, that not all happiness-increasing strategies are created equal, as factors such as administration type (self-administered, group-administered, or one-to-one therapy), length of intervention, and type of sample (self-selected or not selfselected) moderate their efficacy (Sin and Lyubomirsky 2009). The moderators uncovered by the Sin and Lyubomirsky (2009) meta-analysis need to be tested empirically to further understand how these factors influence the success of positive activity interventions. To this end, in addition to examining the main effect of the BPS activity on well-being, the current study also explored two boundary conditions that might affect the efficacy of positive activities - specifically, whether the intervention was administered online or inperson and whether the participant received peer testimonial information communicating the value of the BPS activity.

\subsection{Efficacy of Visualizing Best Possible Selves}

Past research has supported the efficacy of the BPS activity to increase well-being (Boehm et al. 2011a; King 2001; Lyubomirsky et al. 2011; Peters et al. 2010; Sheldon and Lyubomirsky 2006). In the current study, participants who considered their best possible future selves in various important life domains reported significantly greater increases in positive affect than participants who wrote about their past $24 \mathrm{~h}$, thus supporting our hypothesis and replicating previous findings. In further support of our hypothesis, participants who completed the BPS activity reported greater increases in flow experiences and marginally greater increases in feelings of relatedness than those who completed the control activity. Failing to support our hypothesis, however, engaging in the BPS activity did not increase students' feelings of autonomy or competence over engaging in the control activity.

Although we expected all need satisfying feelings to be increased by the BPS activity, we were especially surprised that_-given the goal-directed nature of the writing exercise- 
feelings of autonomy and competence were not bolstered. The failure to boost autonomy and competence was consistent throughout our results, except for the marginal increases in autonomy and competence observed in the Peer Testimonial/Online condition. Because we did not prompt students to actually pursue their goals during the intervention period, it is possible that they did not experience the increases in autonomy and competence typically characterized by goal pursuit (Sheldon and Elliot 1999). The optimism and hope fostered by writing about one's ideal future might be sufficient to increase positive affect (as our results indicated), but may not allow people to honestly answer that they feel more skilled (i.e., competent) or more in control of their lives (i.e., autonomous). Future research should include follow-up items that ask participants whether they have pursued any of the aspirations they described in the BPS writing activity. We expect that participants who have taken steps to pursue their goals will also show increases in autonomy and competence.

The current study focused on the direct impact of the BPS activity on positive affect, need satisfaction, and flow. To our knowledge, our study is the first to examine the direct influence of positive activities on need satisfaction and flow-an important first step in understanding how these underlying mechanisms can causally improve well-being. Because these effects were only established in the short-term, future studies should examine the longer-term influence of happiness activities on positive affect, need satisfaction, and flow. Despite the temporal limitation, even transient experiences of positive affect and related positive psychological constructs may generate upward spirals toward greater well-being (Fredrickson and Joiner 2002).

Accordingly, in the future, it would be instructive to explore the specific mechanisms by which engagement in positive activities increases well-being. We suspect that positive affect, need satisfaction, and flow might serve as important emotional triggers-or mediators-to subsequent increases in people's global evaluations of their lives. One experiment from our laboratory found autonomy and relatedness, but not competence, to mediate increases in satisfaction with life that resulted from expressing gratitude and kindness (Boehm et al. 2011b). In another study, students who were asked to specifically focus on goals that could increase their feelings of autonomy, relatedness, or competence saw greater sustained increases in happiness than students who were asked to focus on goals that could improve their life circumstances (Sheldon et al. 2010). These results suggest that increases in feelings of need satisfaction might precede, and perhaps precipitate, increases in global life evaluation.

We also found that the BPS activity led participants to feel higher levels of flow. Research suggests that people who engage in flow activities are happier than those who engage in activities that pose too little or too much challenge for their skill level (Csikszentmihalyi and Hunter 2003). Csikszentmihalyi (1997) argues that flow can be taught. Thus, people can presumably increase their overall happiness by learning to purposely engage in flow activities. Future investigators could test directly whether increases in flow as a result of a positive activity intervention also lead to subsequent increases in well-being.

In sum, our current results support the ability of positive activities to increase positive affect, relatedness, and flow, especially when participants believe in the efficacy of the activity. Future studies would do well to continue to assess need satisfaction and flow and to include process oriented models and long-term follow-up with participants to consider the potential role of positive affect, need satisfaction, and flow as pathways to increases in global indicators of well-being. 


\subsubsection{Future Directions for Variations of the BPS Activity}

Researchers have started to tailor the BPS activity for specific populations. For example, it may be counterproductive to ask someone who is suffering from a chronic illness or chronic pain (e.g., Smeets and Peters 2011) to imagine their best possible future life without regard to their ill health. An individual's illness is part of her reality, and incorporating her current obstacles into the writing exercise might foster more buy-in from the participant. Further, depressed persons may not be able to imagine that "everything has gone as well as it possibly could" and may need tempered instructions. One study asked depressed participants to imagine themselves in the future, but provided the additional instructions to "imagine you are in a better place where you have resolved some of the issues that are concerning you now" and to "tell yourself the crucial things you realized or the critical steps you took to get there. Give yourself some sage and compassionate advice from a better future" (Shapira and Mongrain 2010, p. 381). Participants who engaged in this modified BPS activity saw greater increases in happiness than a control group who wrote about early memories (Shapira and Mongrain 2010). This variation on the BPS activity instructions seeks to provide a better fit between the activity and participants. Future research should continue to consider small modifications to instructions that might make positive activity interventions more effective for targeted populations.

\subsection{Online Versus In-Person Administration}

We did not find differences in changes in well-being between participants who completed the BPS activity online versus in-person. We suspect that the positive attributes of the online and in-person administration formats offset each other, thus leading the two intervention formats to show similar effects. Participants in the in-person conditions possibly had a more focused and motivating environment in which to complete the writing activity, as they were prompted face to face by an experimenter and not distracted by other activities (e.g., web surfing, Facebook) available on their personal computers. Indeed, research has found that college students use their personal computers for a variety of reasons, including e-mail, shopping, and research for school (Odell et al. 2000), and using computers for personal reasons can interfere with productivity (Mastrangelo et al. 2006). Notably, these distractions were unavailable for the participants in the in-person condition. Further, having to show up in-person and interacting with a research assistant might have made the participants feel that the writing activity was more "official" or worthwhile than if they completed it alone on their personal computer. In contrast, although participants in the online condition lacked the "human element," they may have found the intervention more natural, stress-free, and convenient, as they were able to log-in whenever they felt like during the week. Given the similar effects shown in the online and in-person administration formats, our results lend legitimacy to the use of online formats, which are more cost-effective and hassle-free for researchers and more convenient, comfortable, and accessible for participants.

One caveat, however, is that our "in-person" administration should not be confused with the "group therapy" classification described in the Sin and Lyubomirsky (2009) metaanalysis. The in-person format in our study simply consisted of a research assistant reading the instructions out loud and allowing for any questions that arose; hence, it provided very little direction to participants. Unlike group therapy, the in-person conditions did not include any group discussion or therapeutic guidance from a trained clinician. Although a more personalized intervention format, such as individual or group therapy, would likely 
lead to greater average improvements in well-being than a self-administered approach (Sin and Lyubomirsky 2009), these benefits must be balanced against the anonymity and accessibility afforded by an online, self-administered format.

Access to mental healthcare is not universal-between 2001 and 2003, only $30 \%$ of adults in the U.S. suffering from depression, anxiety, or impulse control disorders received minimally adequate treatment (U.S. Department of Health and Human Services, National Institute of Health 2008). Although access to the Internet is not universal either, greater numbers of people are gaining access through a variety of locations (e.g., home, smartphones, public libraries, work, or Internet cafes; Mitchell et al. 2010), and the cost of using the Internet is a fraction of the high cost of therapy. Furthermore, online interventions are available 24/7, thus making them convenient for participants. They are also anonymous, thus decreasing the potential stigma or discomfort people might face when engaging in happiness-increasing strategies or seeking professional help in general (Layous et al. 2011; Mitchell et al. 2010).

Online intervention formats have great promise to be interactive, animated and personalized in the future (Mitchell et al. 2010). The website used in the current study presented the intervention instructions and measures with no frills. Future interventionists might attempt to make the aesthetics of the site more appealing to the user or use different forms of media to appeal to various learning styles (i.e., including pictures and audio; cf. Kurtz and Lyubomirsky, in press). These effects may bolster the efficacy of engaging in positive activities even further.

\subsection{Perceived Value of Examining One's Best Possible Selves}

Prior research has shown that people who identify with an activity-or find it to be intrinsically valuable - are more motivated to complete it (Deci and Ryan 2000, 2008). Not surprisingly, motivation to engage in a happiness-increasing strategy predicts greater increases in well-being (Lyubomirsky et al. 2011). Extending this research, we sought to manipulate participants' perceptions of the efficacy of the BPS activity by providing (bogus) persuasive testimonials from fellow college students who had gained a great deal from participating in the same activity. Our results showed that students who read the peer testimonials (as opposed to generic passages about campus resources or a control task) reported greater increases in positive affect, relatedness, and flow, but not in autonomy or competence. The testimonials' endorsement of the value of a happiness-increasing activity may have affected participants' beliefs that the activity would be worthwhile and may have helped them identify with the activity, thus making it relatively more intrinsically motivating.

Further analyses revealed that the effect of peer testimonials was driven by the online condition. We conjecture that participants who completed the BPS activity online might have identified more strongly with the testimonials and might have been able to visualize themselves benefiting as much from the BPS activity as the people in the testimonials. Conversely, participants in the in-person conditions read the testimonials in the presence of other fellow college students and may have been relatively more likely to engage in upward social comparisons. For example, instead of believing they too could gain from this activity (like participants in the online condition might have), participants in the in-person conditions may have been relatively more likely to regard a classmate sitting next to them as smarter, more attractive, more ambitious, or more physically fit than they are. Such social comparisons might have undermined the writing activity and caused some participants to second guess whether they could actually achieve the "best possible self" they 
were writing about in the academic, social, career, or health spheres. In contrast, participants who completed the BPS activity on their own computers, likely in privacy, may have been better able to engross themselves in the activity and think optimistically about their abilities, without being sidetracked by pessimistic thoughts borne of unfavorable comparisons.

The peer testimonial manipulation is limited, however, because we did not directly measure participants' perceived efficacy of the BPS activity. We can only infer that the greater benefits observed in the peer testimonial conditions are due to participants' beliefs that the BPS activity is valuable and likely to help them clarify their goals and make progress toward them. Fortunately, evidence from the health domain suggests that testimonials can strongly influence peoples' beliefs. For example, men at risk for Hepatitis B perceived their risk of infection to be greater-and showed higher intentions to get vaccinated-after reading about someone else's experience with the condition than after reviewing statistical evidence (de Wit et al. 2008). Thus, testimonials may persuade people to enact healthy behavioral changes. Future researchers would do well to measure whether, after reading peer testimonial information, people actually do show stronger beliefs in the efficacy of a positive activity — and behave differently while enacting the activity - than people who do not read such an endorsement.

\subsection{Caveats and Limitations}

Due to our study's limitations, our results should be interpreted with caution. First, we used an undergraduate convenience sample. Although our participants were ethnically and socioeconomically diverse, a more representative sample would permit generalization of our findings to individuals from a wider range of ages, educational attainment, occupations, and other life circumstances. Indeed, a particularly important question for future investigators concerns how the effectiveness of positive activities may be moderated by characteristics of the individuals under study (e.g., young vs. old, healthy vs. ill, Western vs. Eastern; Nelson and Lyubomirsky 2012).

Another concern involves our effect sizes. Although many of them are considered small by conventional standards (Cohen 1988), such small effects are comparable or even larger than those found for critical or life-saving treatments, such as aspirin for preventing heart attacks $(r=.03)$ and the Salk vaccine for polio $(r=.01)$ (Rosenthal and Rosnow 2008). Notably, our findings from a single positive activity intervention do not warrant the same weight and import as such life-saving treatments, but even a small effect can be practically important, especially in light of our intervention's low cost, simplicity, and brevity (e.g., 15 min weekly in the online conditions). A binomial effect size display (BESD) further illustrates our findings' practical importance. For example, for our finding that the BPS activity boosted positive affect $(r=.17)$, the BESD demonstrates that 59 out of 100 hypothetical individuals who complete the BPS activity would experience gains in positive affect, relative to only 41 out of 100 individuals who complete a control activity.

\section{Conclusions}

Now that research evidence convincingly supports the efficacy of positive activity interventions to increase well-being (Sin and Lyubomirsky 2009), investigators have turned their attention to potential boundary conditions that might affect the magnitude of this efficacy (Lyubomirsky et al. 2005b). For example, the frequency (Lyubomirsky et al. 
2005b) and variety (Sheldon et al., in press) with which a happiness-increasing strategy is administered can make it more or less effective. Similarly, characteristics of the person engaging in a positive activity also affect the activity's success, such that people who choose to pursue happiness (Lyubomirsky et al. 2011), put forth greater effort into that pursuit (Lyubomirsky et al. 2011), or reside in a culture in which personal happiness is valued (Boehm et al. 2011a) all benefit more from the practice of positive activities than people who do not share these characteristics. Of course, many questions remain to be explored. For example, investigators need to consider the extent to which the intervention type and format matches an individual's needs and preferences (i.e., person-activity fit). Finally, more research should pay attention to the "why" question-that is, what are the precise mechanisms underlying the success (or failure) of positive activity interventions to increase happiness.

The current study sought to extend previous research by further exploring the critical factors that impact the efficacy of happiness-increasing strategies-in other words, to establish at least one optimal way to deliver a positive activity intervention. Our findings, however, hold implications not only for scientists but for individual happiness seekers and mental health practitioners. In a nutshell, we found that successful positive activity interventions can be delivered online (obviating the need for potentially expensive, timeconsuming, or inconvenient treatment) and-perhaps not surprisingly-are maximally effective when championed or endorsed by peers.

\section{References}

Armstrong, A. W., Idriss, N. Z., \& Kim, R. H. (2011). Effects of video-based, online education on behavioral and knowledge outcomes in sunscreen use: A randomized controlled trial. Patient Education and Counseling, 83, 273-277.

Boehm, J. K., Lyubomirsky, S., \& Sheldon, K. M. (2011a). A longitudinal experimental study comparing the effectiveness of happiness-enhancing strategies in Anglo Americans and Asian Americans. Cognition and Emotion, 25, 1152-1167.

Boehm, J. K., Lyubomirsky, S., \& Sheldon, K. M. (2011b). The role of need satisfying experiences in a positive activity intervention with Anglo Americans and Asian Americans. Unpublished raw data.

Carrard, I., Crepen, C., Rouget, P., Lam, T., Golay, A., \& Van der Linden, M. (2011). Randomised controlled trial of a guided self-help treatment on the internet for binge eating disorder. Behaviour Research and Therapy, 49, 482-491.

Cohen, J. (1988). Statistical power analysis for the behavioral sciences (2nd ed.). Hillsdale, NJ: Erlbaum.

Collinson, A., Lindley, R., Campbell, A., Waters, I., Lindley, T., \& Wallace, A. (2010). An evaluation of an internet-based approach to weight loss with low glycemic principles. Journal of Human Nutrition \& Dietetics, 24, 192-195.

Csikszentmihalyi, M. (1990). Flow: The psychology of optimal experience. New York: Harper \& Row.

Csikszentmihalyi, M. (1997). Finding flow: The psychology of engagement with everyday life. New York: Basic Books.

Csikszentmihalyi, M. (1999). If we are so rich, why aren't we happy? American Psychologist, 54, 821-827.

Csikszentmihalyi, M., \& Hunter, J. (2003). Happiness in everyday life: The uses of experience sampling. Journal of Happiness Studies, 4, 185-199.

Deci, E. L., \& Ryan, R. M. (2000). The "what" and "why" of goal pursuits: Human needs and the selfdetermination of behavior. Psychological Inquiry, 11, 227-268.

Deci, E. L., \& Ryan, R. M. (2008). Self-determination theory: A macrotheory of human motivation, development, and health. Canadian Psychology, 49, 182-185.

de Wit, J. B. F., Das, E., \& Vet, R. (2008). What works best: Objective statistics or a personal testimonial? An assessment of the persuasive effects of different types of message evidence on risk perception. Health Psychology, 27, 110-115.

Diener, E. (2000). Subjective well-being: The science of happiness and a proposal for a national index. American Psychologist, 55, 34-43. 
Diener, E., \& Emmons, R. A. (1985). The independence of positive and negative affect. Journal of Personality and Social Psychology, 47, 1105-1117.

Diener, E., Oishi, S., \& Lucas, R. E. (2009). Subjective well-being: The science of happiness and life satisfaction. In C. R. Snyder \& S. J. Lopez (Eds.), Oxford handbook of positive psychology (pp. 187-194). Oxford: Oxford University Press.

Emmons, R. A., \& McCullough, M. E. (2003). Counting blessings versus burdens: An experimental investigation of gratitude and subjective well-being in daily life. Journal of Personality and Social Psychology, 84, 377-389.

Frattaroli, J. (2006). Experimental disclosure and its moderators: A meta-analysis. Psychological Bulletin, $132,823-865$.

Fredrickson, B. L., \& Joiner, T. (2002). Positive emotions trigger upward spirals toward emotional wellbeing. Psychological Science, 13, 172-175.

Hester, R. K., Delaney, H. D., \& Campbell, W. (2011). Moderatedrinking.com and Moderation Management: Outcomes of a randomized controlled trial with non-dependent problem drinkers. Journal of Consulting and Clinical Psychology, 79, 215-222.

King, L. A. (2001). The health benefits of writing about life goals. Personality and Social Psychology Bulletin, 27, 798-807.

King, L. A., \& Miner, K. N. (2000). Writing about the perceived benefits of traumatic events: Implications for physical health. Personality and Social Psychology Bulletin, 26, 220-230.

Kurtz, J. L., \& Lyubomirsky, S. Positive psychology. In M. R. Mehl \& T. S. Conner (Eds.), Handbook of research methods for studying daily life. New York: Guilford Press (in press).

Layous, K., Chancellor, J., Lyubomirsky, S., Wang, L., \& Doraiswamy, P. M. (2011). Delivering happiness: Translating positive psychology intervention research for treating major and minor depressive disorders. Journal of Alternative and Complementary Medicine, 17, 675-683.

Lyubomirsky, S., Dickerhoof, R., Boehm, J. K., \& Sheldon, K. M. (2011). Becoming happier takes both a will and a proper way: An experimental longitudinal intervention to boost well-being. Emotion, 11, 391-402.

Lyubomirsky, S., King, L., \& Diener, E. (2005a). The benefits of frequent positive affect: Does happiness lead to success? Psychological Bulletin, 131, 803-855.

Lyubomirsky, S., Sheldon, K. M., \& Schkade, D. (2005b). Pursuing Happiness: The architecture of sustainable change. Review of General Psychology, 9, 111-131.

Maris, E. (1998). Covariance adjustment versus gain scores-revisited. Psychological Methods, 3, 309-327.

Martin, B. A. S., Wentzel, D., \& Tomczak, T. (2008). Effects of susceptibility to normative influence and type of testimonial on attitudes toward print advertising. Journal of Advertising, 37, $29-43$.

Mastrangelo, P. M., Everton, W., \& Jolton, J. (2006). Personal use of work computers: Distraction versus destruction. CyberPsychology and Behavior, 9, 730-741.

Mauss, I. B., Tamir, M., Anderson, C. L., \& Savino, N. S. (2011). Can seeking happiness make people unhappy? Paradoxical effects of valuing happiness. Emotion, 11, 807-815.

Meyer, B., Berger, T., Caspar, F., Beevers, C. G., Andersson, G., \& Weiss, M. (2009). Effectiveness of a novel integrative online treatment for depression (Deprexis): Randomized controlled trial. Journal of Medical Internet Research, 11, e15. Retrieved from: http://www.ncbi.nlm.nih.gov/pmc/articles/ PMC2762808/.

Mitchell, J., Vella-Brodrick, D., \& Klein, B. (2010). Positive psychology and the internet: A mental health opportunity. Electronic Journal of Applied Psychology, 6, 30-41.

Moore, B. A., Fazzino, T., Garnet, B., Cutter, C. J., \& Barry, D. T. (2011). Computer based interventions for drug use disorders: A systematic review. Journal of Substance Abuse Treatment, 40, 215-223.

Nakamura, J., \& Csikszentmihalyi, M. (2009). Flow theory and research. In C. R. Snyder \& S. Lopez (Eds.), Oxford handbook of positive psychology (pp. 195-206). New York: Oxford University Press.

Nelson, S. K., \& Lyubomirsky, S. (2012). Finding happiness: Tailoring positive activities for optimal wellbeing benefits. In M. Tugade, M. Shiota, \& L. Kirby (Eds.), Handbook of positive emotions. New York: Guilford (to appear).

Niemiec, C. P., Ryan, R. M., \& Deci, E. L. (2009). The path taken: Consequences of attaining intrinsic and extrinsic aspirations in post-college life. Journal of Research in Personality, 43, 291-306.

Odell, P. M., Korgen, K. O., Schumacher, P., \& Delucchi, M. (2000). Internet use among female and male college students. Cyber Psychology and Behavior, 3, 855-862.

Pennebaker, J. W., \& Beall, S. K. (1986). Confronting a traumatic event: Toward an understanding of inhibition and disease. Journal of Abnormal Psychology, 95, 274-281.

Pennebaker, J. W., Colder, M., \& Sharp, L. K. (1990). Accelerating the coping process. Journal of Personality and Social Psychology, 58, 528-537.

Pennebaker, J. W., \& Seagal, J. D. (1999). Forming a story: The health benefits of narrative. Journal of Clinical Psychology, 55, 1243-1254. 
Peters, M. L., Flink, I. K., Boersma, K., \& Linton, S. J. (2010). Manipulating optimism: Can imagining a best possible self be used to increase positive future expectancies? The Journal of Positive Psychology, 5, 204-211.

Rogosa, D. (1988). Myths about longitudinal research. In K. W. Schaie, R. T. Campbell, W. Meredith, \& S. C. Rawlings (Eds.), Methodological issues in aging research (pp. 171-209). New York: Springer.

Rosenthal, R., \& Rosnow, R. L. (2008). Essentials of behavioral research (3rd ed.). Boston, MA: McGrawHill, Inc.

Rosenthal, R., Rosnow, R. L., \& Rubin, D. B. (2000). Contrasts and effect sizes in behavioral research. Cambridge, UK: Cambridge University Press.

Ryan, R. M., \& Deci, E. L. (2008). Self-determination theory and the role of basic psychological needs in personality and the organization of behavior. In O. P. John, R. W. Robins, \& L. A. Pervin (Eds.), Handbook of personality psychology: Theory and research (3rd ed., pp. 654-678). New York: Guilford Press.

Seligman, M. E. P. (2011). Flourish: A visionary understanding of happiness and well-being. New York: Free Press.

Seligman, M. E. P., Steen, T. A., Park, N., \& Peterson, C. (2005). Positive psychology progress: Empirical validation of interventions. American Psychologist, 60, 410-421.

Shapira, L. B., \& Mongrain, M. (2010). The benefits of self-compassion and optimism exercises for individuals vulnerable to depression. The Journal of Positive Psychology, 5, 377-389.

Sheldon, K. M. (2004). Optimal human being: An integrated multi-level perspective. Mahwah, NJ: Erlbaum.

Sheldon, K., Abad, N., Ferguson, Y., Gunz, A., Houser-Marko, L., Nichols, C. P., et al. (2010). Persistent pursuit of need-satisfying goals leads to increased happiness: A 6-month experimental longitudinal study. Motivation and Emotion, 34, 39-48.

Sheldon, K. M., \& Elliot, A. J. (1999). Goal striving, need-satisfaction, and longitudinal well-being: The Self-Concordance Model. Journal of Personality and Social Psychology, 76, 482-497.

Sheldon, K. M., Elliot, A. J., Kim, Y., \& Kasser, T. (2001). What is satisfying about satisfying events? Testing 10 candidate psychological needs. Journal of Personality and Social Psychology, 80, 25-339.

Sheldon, K. M., Boehm, J. K., \& Lyubomirsky, S. Variety is the spice of happiness: The hedonic adaptation prevention (HAP) model. In I. Boniwell, \& S. David (Eds.), Oxford handbook of happiness. Oxford: Oxford University Press (in press).

Sheldon, K. M., \& Krieger, L. K. (2007). Understanding the negative effects of legal education on law students: A longitudinal test and extension of self-determination theory. Personality and Social Psychology Bulletin, 33, 883-897.

Sheldon, K. M., \& Lyubomirsky, S. (2006). How to increase and sustain positive emotion: The effects of expressing gratitude and visualizing best possible selves. The Journal of Positive Psychology, 1, 73-82.

Sin, N. L., \& Lyubomirsky, S. (2009). Enhancing well-being and alleviating depressive symptoms with positive psychology interventions: A practice-friendly meta-analysis. Journal of Clinical Psychology: In Session, 65, 467-487.

Smeets, E. \& Peters, M. (2011, July). An online positive psychology intervention for chronic pain patients: Preliminary data from a randomized controlled clinical trial. In Symposium conducted at the Second World Congress on Positive Psychology in Philadelphia, PA.

U.S. Department of Health and Human Services, National Institute of Health (2008). National healthcare disparities report. Retrieved from http://www.ahrq.gov/qual/nhdr08/nhdr08.pdf.

Wainer, H. (1991). Adjusting for differential base rates: Lord's paradox again. Psychological Bulletin, 109, 147-151. 